\title{
Escrever sob o fascínio da imagem - ressonâncias entre o pensamento de Maurice Blanchote Georges Didi-Huberman
}

\section{LILIAN HACK \\ ÉDIO RANIERE DA SILVA}

\section{Resumo}

O artigo problematiza o conceito de imagem a partir do pensamento de Maurice Blanchot e Georges Didi-Huberman. Explorando especialmente os conceitos de duplicidade da imagem em Blanchot e dupla distância do olhar em DidiHuberman, pretende-se verificar os pontos em que se faz convergir nesses autores um modo de operar o pensamento e a escrita sobre a arte em sua relação com a imagem. Nesse jogo, sujeito e objeto são lançados a uma instabilidade, movimento em que o sujeito se desfaz de si mesmo pela imagem, se desfaz de si no encontro com uma obra. Momento em que a imagem solicita a palavra e em que a língua torna-se o lugar desde onde podemos nos aproximar dela. 


\title{
Writing under the fascination of image - resonances between the thought of Maurice Blanchot and Georges Didi- Huberman
}

\author{
LILIAN HACK \\ ÉDIO RANIERE DA SILVA
}

\begin{abstract}
The article problematizes the concept of image from the thinking of Maurice Blanchot and Georges Didi-Huberman. Exploring especially the concepts of duplicity of the image in Blanchot and double distance of the look in Didi-Huberman, it is intended to compose a starting plan that will allow to verify the points in which one converges in these authors a way of operating the thought about art in its relation to the image. In this game subject and object are thrown into an instability, a movement in which the subject undoes himself by the image, he discards himself in the encounter with a work. Moment when the image asks for the word and where the language becomes the place from which we can approach it.
\end{abstract}




\section{Escribir bajo el fascinio de la imagen - resonancias entre el pensamiento de Maurice Blanchoty Georges Didi-Huberman}

\section{PELÓPIDAS CYPRIANO PEL \\ RICARDO ZANI}

\section{Resumen}

El artículo problematiza el concepto de imagen a partir del pensamiento de Maurice Blanchot y Georges DidiHuberman. Examinando especialmente los conceptos de duplicidad de la imagen en Blanchot y doble distancia de la mirada en Didi-Huberman, se pretende verificar los puntos en los que se hace converger en esos autores un modo de operar el pensamiento y la escritura sobre el arte en su relación con la imagen. En ese juego, sujeto y objeto son lanzados a una inestabilidad, movimiento en que el sujeto se deshace de sí mismo por la imagen, se deshace de sí en el encuentro con una obra. Momento en el que la imagen pide la palabra y en el que la lengua se convierte en el lugar desde donde podemos acercarnos a ella.

Palabras clave:

Blanchot, Didi-Huberman, imagen. 


\section{O Fascínio da Imagem}

O pensamento de Maurice Blanchot, situado dentro da filosofia, teoria e crítica literária, não cessa de dedicar diferentes reflexões à questão da imagem. Segundo afirma o historiador e crítico de arte francês Georges Didi-Huberman (2011, p. 26), os escritos de Blanchot "trazem sempre, em suas margens - entradas ou saídas - alguma poderosa invocação às imagens". Seria assim que um de seus livros mais importantes - O Espaço Literário (2011) - se desenvolve até fazer da imagem, isoladora e fascinante, o lugar e a questão próprios engajados no ato de escrever, como observa Didi-Huberman.

Tomando como ponto de partida essas afirmações de um dos mais reconhecidos pensadores da arte e da imagem no contemporâneo, desejamos avançar sobre as margens abertas por elas que nos mostram a direção que este autor toma quando se refere ao pensamento de Maurice Blanchot, não apenas para pensar a imagem, mas igualmente para pensar a escrita que envolve a arte, seja a escrita da história, da teoria ou da crítica de arte, uma escrita que não cessa de buscar nela mesma seu lugar de criação, uma poética da palavra que olha para a imagem. Desejamos dar assim atenção especial à relação que se estabelece entre palavra e imagem no que toca à escrita em ambos os autores, nos colocando à espreita do conceito de imagem que é suspenso pelos dois ou que podemos situar a partir de seus escritos aqui selecionados. Ensejamos especialmente expor o modo como cada um problematiza a imagem diante da palavra, dando a ver seus pontos em comum, mas procurando pelo giro que coloca em cena a escrita que se dedica à arte. E se, como escreve Blanchot, o giro critica, nosso giro contorna 
também a escrita elaborada pela crítica, reconhecendo essa escrita como aquela que inventa palavras às obras visuais e que por sua vez inventa uma obra em seu ato/gesto de escrita. Em Blanchot esse "giro" é o que coloca a palavra fora da linguagem, abre-a ao verso, à prosa, à poesia - errância da palavra. Aproximamos esse giro da palavra da crítica de arte, pois ela não é estranha a essa curva que é a volta da "história", busca da palavra que nos coloca diante das obras no presente, mas ao mesmo tempo se realiza fora de todo presente. "Toda busca é uma crise”, escreve Blanchot (2001, p. 72), assim é a própria busca da crítica diante de palavras que possam falar, escrever, atingir uma imagem, uma obra de arte. Nessa busca por palavras à obra, "o que é procurado nada mais é do que o giro da busca, que faz acontecer a crise: o giro critica" (BLANCHOT, 2001, p. 72).

O percurso que se contorna neste ensaio pretende percorrer um método que, por um lado, consiste em uma genealogia dos conceitos em relação aos seus autores e, por outro, em uma arqueologia dos sentidos da escrita que se dedica à arte, compreendida como escavação na superfície do papel: a escrita como corte, estilete que desenha um estilo, um modo de operar diante das palavras, em suas camadas.

\section{A Duplicidade da Imagem}

Escrevemos sob o fascínio da imagem. É o que repete incessantemente Maurice Blanchot, ainda que de maneiras por vezes disfarçadas, em seu livro O Espaço Literário (2011). Mas esse pensamento não hierarquiza ou opõe as relações entre palavra e imagem. Em Falar, não é ver, capítulo de seu livro A Conversa Infinita - A Palavra Plural (2001), ele pergunta precisamente isso: "Por que a coisa deveria ser então separada entre a coisa que se vê e a coisa que se diz (se escreve)?" (BLANCHOT, 2001, p. 68). Em um primeiro nível podemos pensar que não se trata de separar porque uma remeteria à outra. No entanto, nessa pergunta está implícita a compreensão de que escrever não é expor a palavra ao olhar, a palavra não se apresenta como uma palavra, mas como uma visão liberta das limitações da visão, como escreve Blanchot (2001, p. 69): "A palavra (pelo menos a que interessa: a escrita) desnuda sem mesmo retirar o véu, e às vezes, ao contrário (perigosamente), encobrindo - de uma maneira que não cobre nem descobre". A palavra escrita - escrever é escavar, na etimologia corrente a escrita é corte, estilete que desenha a palavra em uma super- 
fície - é arrastada pelo fascínio da imagem, sendo assim ela mesma uma imagem dessa fascinação.

Portanto, em Blanchot, a palavra não revela algo em relação à imagem: "temo que revelar seja um termo inadequado. Revelar, tirar o véu, expor diretamente à visão" (BLANCHOT, 2001, p. 69). Isso porque na imagem não há nada que necessite ser "revelado" pela palavra. Não há mistério ou invisível da imagem a ser desvendado, respondido ou tornado visível pela palavra. A palavra, como a imagem, também entra em contato com visibilidades, é também ela produto de um regime de visibilidade, tal qual nos fala Foucault (2007). Em Blanchot, palavra e imagem estão em uma relação que é não-relação, elas não se encontram em um encadeamento hierárquico, nem disputam territórios, mas colocam-se cada uma em um processo singular de apresentação, ou seja, tornam uma visibilidade determinada presente ao olhar. Nesse regime da visibilidade palavra e imagem não se encontram no lugar de alguma outra coisa, como no regime da representação.

No entanto, "a imagem", afirma o filósofo neste mesmo texto, "é a duplicidade da revelação" (BLANCHOT, 2001, p. 69). A partir daqui podemos perguntar: a que enfim se deve esse conceito de revelação em relação à imagem? Qual seria essa duplicidade da revelação na imagem? Encontramos alguns caminhos possíveis à busca que nos lançamos com essas perguntas voltando a $O$ Espaço Literário, no qual teremos um primeiro desenho ao conceito de imagem, tal como a podemos compreender em Blanchot.

Segundo ele, quando estamos diante das próprias coisas, se fixamos um rosto ou um canto de parede, por exemplo, subitamente poderíamos nos abandonar no que vemos, estar entregues àquela visão, olhos fixos no objeto, como que impassíveis diante de sua presença. Mas precisamente esse instante em que fixamos a coisa, coincidiria com a imagem: "É então que a coisa que fixamos mergulhou na sua imagem, é que a imagem uniu-se a esse fundo de impotência onde tudo recai" (BLANCHOT, 2011, p. 257). É como se houvesse um campo obscuro em torno desse olhar fixo, que ao mesmo tempo o fizesse recair sobre o dia, sobre uma claridade. Momento em que um objeto, uma superfície, torna-se imagem. Desse exemplo pode-se destacar a duplicidade da imagem: por um lado sua relação com a representação, com a verdade, e por outro, sua relação com a ausência como presença, com uma suspensão.

Podemos avançar ainda um pouco: por um lado a imagem, segundo o pensamento comum, está depois do objeto, 
como se fosse a sua continuação: vemos, depois imaginamos. Esse "depois" significaria que o objeto deve distanciar-se para enfim deixar-se recapturar. Aqui a imagem pode ajudar-nos a recuperar idealmente a coisa, nesse caso ela é a sua "negação vivificante". Aqui os sentidos da imagem se fixam: estaríamos no campo da representação. A imagem seria possibilidade de entendimento: "o sentido escapa sempre para um outro sentido, o mal-entendido serve ainda à compreensão" (BLANCHOT, 2011, p. 265). Blanchot nos sugere que seria essa a atitude diante da imagem que a versão estética da compreensão da imagem representada pelo ideal da arte clássica solicitaria, mais especialmente em sua teoria:

A arte clássica, fazendo sua glória através da tarefa de relacionar a semelhança com um rosto e a imagem com um corpo tornava a imagem negação vivificante, capaz de negar a natureza, elevá-la a um sentido superior, ora para conhecê-la, ora para usufruir dela na admiração. [...] Assim, a arte era simultaneamente ideal e verdadeira, fiel à figura e fiel à verdade que é sem figura (BLANCHOT, 2011, p. 262).

Ou seja, na arte clássica o que estava em jogo era o entendimento estético que possibilitava uma compreensão da obra através de um sistema de representação, em que se acreditava ser possível uma compreensão da verdade pela obra, posto que a figuração seria fiel à verdade e, ao mesmo tempo, ideal.

Por outro lado, nessa duplicidade que lhe é própria a imagem também pode nos devolver não mais a coisa ausente, mas a ausência como presença, ao "duplo neutro do objeto em que a pertença ao mundo se dissipou”, como escreve Blanchot (2011, p. 265). Aqui os sentidos escapam perpetuamente, ou melhor, "o sentido não escapa para um outro sentido, mas no outro de todos os sentidos", e assim "nada tem sentido, mas tudo parece ter infinitamente sentido" (BLANCHOT, 2011, p. 265). É preciso ressaltar, não se trata de uma pluralidade de sentidos ou significados da imagem, mas de um sentido sempre original da mesma. Observamos o sentido que Maurice Blanchot dá a esse conceito: essa origem da imagem não se confunde com o momento de sua elaboração técnica, tampouco se confunde com um sujeito que a tenha produzido, mas diz de sua condição de pronunciar infinitamente a palavra começo: "a origem a atrai para onde ela arrisca a perder-se, e porque deve escapar, mediante um salto, à insistência implacável do que não tem começo nem fim" (BLANCHOT, 2011, p. 267). Para 
Blanchot esse momento em que um objeto "torna-se imagem" não significa que ele tenha se tornado outro, mas ao torná-lo imagem o converteríamos no inapreensível:

A coisa estava aí, que nós apreenderíamos no movimento vivo de uma ação compreensiva e, tornada imagem, ei-la instantaneamente convertida no inapreensível, inatual, impassível, não a mesma coisa distanciada, mas essa coisa como distanciamento, a coisa presente em sua ausência, a apreensível porque inapreensível, aparecendo na qualidade de desaparecida, o retorno do que não volta, o coração estranho do longínquo como vida e coração único da coisa (BLANCHOT, 2011, p. 257).

O valor e o significado desse objeto se tornam assim suspensos, porque a verdade nele recua no instante em que ele torna-se imagem. Aqui a imagem nada tem a ver com a significação, com o sentido do objeto: "a imagem de um objeto não somente não é o sentido desse objeto e não ajuda na sua compreensão, mas tende a subtraí-los na medida em que o mantém na imobilidade de uma semelhança que nada tem com que se assemelhar" (BLANCHOT, 2011, p. 262). Por isso, na imagem, o sentido que escapa faz com que ele se torne infinitamente rico, ou seja, infinitamente aberto.

Isso significa dizer que ora a imagem serve à verdade do mundo, quando se acredita que ela se segue ao objeto, retornando a ele idealmente, quando a imagem guarda algo daquilo que desaparece: aqui a imagem mantém uma relação com a semelhança e com a significação - o pensamento comum, a vida prática, exige esta inversão da imagem: trata-se do campo da representação. Ora a imagem subtrai o sentido, mantendo o objeto na imobilidade de uma semelhança com nada ou consigo mesmo. Não mais se trata do objeto ausente, mas da ausência como presença. Para Blanchot este é o duplo neutro do objeto, em que o pertencimento ao mundo se dissipou.

Podemos ainda expor essa proposição da seguinte maneira: Blanchot (2011, p. 255) afirma que a imagem pede a neutralidade e a supressão do mundo, ela "quer que tudo reentre no fundo indiferente onde nada se afirma, tende para a intimidade do que ainda subsiste no vazio: está aí a sua verdade". Mas essa verdade excede a própria imagem, ou seja, o que torna a imagem possível é o limite em que ela cessa. É como se a imagem estivesse suspensa no vazio e nele reentrasse. Daí resulta a ambiguidade que a imagem anuncia e "a mentira brilhante 
que se lhe recrimina" (BLANCHOT, 2011, p. 255). Isso significaria dizer que a imagem escava um fundo indiferente no qual nada se afirma. É mesmo como se a imagem surgisse pela escavação de um buraco, profundidade que não se pode atingir, mas que não cessa de envolver aquele que escava. Então se abre um buraco, mas também nele se precipita uma queda vertiginosa, que aprofunda - naquele que escava e se precipita - o vazio, como aquilo que faz escapar os sentidos.

A duplicidade da imagem provém, portanto, de um duplo sentido original que traz consigo a potência do negativo - intimidade da imagem com a morte: "do fato de que a morte é ora trabalho da verdade no mundo, ora a perpetuidade do que não suporta começo nem fim" (BLANCHOT, 2011, p. 263). Em Blanchot, a imagem está em intimidade com a morte, pois "a imagem, à primeira vista, não se assemelha ao cadáver, mas poderia muito bem ser que a estranheza cadavérica fosse também a da imagem" (BLANCHOT, 2011, p. 257). O cadáver e sua imagem servem a uma fórmula que permite uma compreensão da imagem nessa dispersão. Isso porque o cadáver que podemos olhar como reflexo de sua vida refletida, no entanto, não se assemelha a nada mais, ele faz passar seu "valor de uso e de verdade" para algo "incrível - incomum e neutro" (BLANCHOT, 2011, p. 260). Porém, paradoxalmente, o cadáver é a semelhança plena, num grau absoluto, perturbador e maravilhoso, justamente porque a nada se assemelha. Poderíamos acreditar que um cadáver se assemelha a si mesmo, como o homem seria feito à sua imagem, entretanto, na fórmula invertida por Blanchot (2011, p. 262), "o homem é desfeito segundo a sua imagem”. A imagem de um cadáver não se assemelha ao sujeito morto, pois, como escreve Didi-Huberman (2011, p. 29), "ela o deixa em sua dispersão primeira, em seu equívoco fatal, em sua necessária inacessibilidade”.

Por analogia, Blanchot aproxima essas definições da semelhança cadavérica à semelhança do utensílio, do objeto que perdeu seu valor de uso: "o utensílio, não mais aparecendo no seu uso, aparece. Essa aparência do objeto é a da semelhança e do reflexo: e se se preferir, o seu duplo" (BLANCHOT, 2011, p. 283). E podemos crer que tal seria a categoria dos objetos apropriados pela arte. Retirados ou mesmo excluídos da esfera do uso, eles aparecem:

A arte está ligada a essa possibilidade para os objetos de 'aparecer', isto é, de se abandonar à pura e simples semelhança por trás da qual nada existe - exceto o ser. Só aparece o que 
se entregou à imagem, e tudo o que aparece é, nesse sentido, imaginário (BLANCHOT, 2011, p. 283, grifo do autor).

Quando o valor e o significado do objeto são suspensos, quando o mundo o abandona à ociosidade e o coloca de lado, a verdade nele recua, o elementar reivindica-o, empobrecimento que se torna enriquecimento do objeto, que o consagra como imagem. Na arte, portanto, o objeto "aparece" quando entregue à sua imagem, e a relação que com ele podemos estabelecer provém, nesse sentido, do imaginário. Na arte, como na noite - aquela mesma noite que se abre em Blanchot, na reivindicação do espaço literário, quando a busca de Orfeu consagrada à Eurídice é a busca da arte - as coisas perdem seus contornos: instante em que se afirmam em seu desaparecimento, consagradas à imagem.

Essa duplicidade da imagem tal qual observamos em Blanchot até aqui não se refere a uma escolha possível, ou seja, não se pode pacificar essa duplicidade acreditando que seria a própria imagem que se nos oferece a partir de um desses lugares e que assim poderíamos escolher entre um e outro. Essa duplicidade implica uma ambiguidade da imagem, ou seu duplo sentido original, que remete às duas versões do imaginário, como nos sugere o filósofo: ao nível do mundo - no nível representacional - essa ambiguidade é a possibilidade de entendimento, já em outro nível - no nível em que a imagem pode encontrar-se com a arte - a imagem nos introduz ao meio indeterminado da fascinação, concedendo o poder de dispor das coisas em sua ausência e pela ficção.

Essa duplicidade, é preciso esclarecer ainda uma vez mais, não se refere a um duplo do objeto projetado pela imagem, o jogo platônico da imagem como mera sombra do real é desmantelado nessa reivindicação da imagem realizada por Blanchot, essa duplicidade se refere ao "desdobramento inicial que permite em seguida a figuração da coisa” (BLANCHOT, 2001, p. 69). E essa figuração pode pertencer a um jogo de semelhança ou dessemelhança: essa duplicidade é, por um lado, o jogo forçoso da representação, do semelhante, e, por outro, o jogo da criação, da invenção de sentidos provocados e oferecidos especialmente pela arte, jogo da dessemelhança. É justamente nesse desdobramento da duplicidade da imagem que se encontram as duas versões do imaginário, que são o vergamento, as curvas que dobram a imagem, que é a versão sempre em processo de inversão. Esse vergamento, essa curva que dobra a imagem, a carrega em uma divergência, uma 
ambiguidade, mas que não se refere à possibilidade de uma escolha na imagem, uma escolha do sujeito que olha. Essas duas versões do imaginário são produzidas, inventadas na relação, uma relação que nos atravessa, que solicita um olhar, que solicita um sujeito que ao mesmo tempo se desfaz de si mesmo pela imagem.

\section{Viver um Evento em Imagem}

A imagem fala menos das coisas do que de nós mesmos, ou como escreve Blanchot (2011, p. 256), "de menos que nós", porque também nos coloca em contato com o esquecimento: "esquecimento de si no mundo". Uma espécie de esquecimento estético é o que nos lembra o artista esloveno Evgen Bavcar. Em entrevista concedida a Elida Tessler e Muriel Caron, quando perguntado sobre por que o Quadrado Negro de Casimir Malévitch lhe é tão importante, ele responde o seguinte:

Por que este quadro é o encontro com o olhar suposto. Todo pintor digno deste nome, um dia ou outro, encontra em sua vida este ponto fundamental das trevas, isto é, lá onde há um apagamento das realidades, uma espécie de, como diria Nietzsche, esquecimento estético. Um esquecimento estético que passa pelas trevas, e que é necessário para reencontrar a face do outro (BAVCAR, 2001, p. 31).

Poderíamos dizer que a imagem tem lugar - torna-se um acontecimento - quando nos desfazemos de nós mesmos no encontro com o outro, outro que está contido no próprio olhar - olhar suposto. Seria assim que a imagem, em intimidade com as trevas, com a escuridão da noite, falaria intimamente de nós mesmos, mas apenas porque, segundo Blanchot, ela designaria esse nível em que, na vizinhança de um exterior vago e vazio - como a noite - a intimidade da pessoa se rompe.

Talvez seja a isso o que Blanchot chama "viver um evento em imagem", quando aquilo que "nos acontece apodera-se de nós, como nos empolgaria a imagem, ou seja, nos despoja, dela e de nós, mantém-nos fora, faz desse exterior uma presença em que o 'Eu' não 'se' reconhece" (BLANCHOT, 2011, p. 264). Viver um evento em imagem não é ter desse evento uma imagem, tampouco oferecer-lhe uma imagem. Viver um evento em imagem não será desligar-se desse evento, desinteressar-se dele numa passividade de olhar, "como queriam a versão estética da imagem no ideal sereno da arte clássica" 
(BLANCHOT, 2011, p. 263). Viver um evento em imagem seria experimentar, nessa distância com a qual a imagem nos coloca em contato, outra maneira de dispor das coisas. Seria o momento em que nos prendemos a esse evento, pois não nos envolvemos a ele por uma decisão livre. Viver um evento em imagem seria então:

[...] passar da região do real, onde nos mantemos a distância das coisas para melhor dispor delas, para essa outra região onde a distância nos detém, essa distância que é então profundidade não viva, indisponível, lonjura inapreciável que se torna como que a potência soberana e derradeira das coisas. (BLANCHOT, 2011, p. 263).

Seria nesse momento em que nos envolvemos tão profundamente com as coisas, com os objetos - uma aproximação na distância -, que nos aproximaríamos de nós mesmos para neles nos tornarmos. Tão fascinados e apaixonados estaríamos pela imagem, entregues pela sua distância e esquecimento, que, subitamente, nela nos tornamos:

Longe de nos deixar fora de causa e de nos fazer viver na fantasia gratuita, [a imagem] parece entregar-nos profundamente a nós mesmos. Íntima é a imagem porque ela faz de nossa intimidade uma potência exterior a que nos submetemos passivamente: fora de nós, no recuo do mundo que ela provoca, situa-se, desgarrada e brilhante, a profundidade de nossas paixões (BLANCHOT, 2011, p. 263).

Poderíamos afirmar, dessa forma, que somos imagens, mas apenas por um breve instante, nas imagens através das quais nos desfazemos. Um pequeno território, logo desterritorializado. Assim, este é o momento em que, ao mesmo tempo em que nos entregamos a nós mesmos pela imagem, nos desvencilhamos de nós, posto que entramos em contato profundo com o outro, com esse lado de fora - fora de nós. Momento que a arte admite e provoca com frequência.

A respeito dessas reflexões, o pensamento sobre a imagem de Evgen Bavcar, mais uma vez, possui uma precisão de olhar inconfundível. Na mesma entrevista citada acima, ele afirma que uma imagem não é forçosamente visual. Segundo ele, todo cego tem direito de dizer "eu me imagino", e se imaginar, é ter imagens. Ele ainda afirma que ninguém vê, nunca, sua imagem real, concreta: 
Todo mundo se utiliza do olhar do outro, só que sobre outros planos, sem se dar conta sempre. Percepção não é aquilo que vemos, mas a maneira como abordamos o fato de ver. E como não se pode nunca ver com os próprios olhos, somos todos um pouco cegos. Nós nos olhamos sempre com o olhar do outro, mesmo que seja aquele do espelho (BAVCAR, 2001, p. 32 ).

Isso tudo lembra perfeitamente o que escreve Maurice Blanchot:

A partir do momento em que estamos fora de nós - nesse êxtase que é a imagem - o 'real' entra num reino equívoco onde já não existe limite nem intervalo, nem momentos, e onde cada coisa, absorvida no vazio de seu reflexo, aproxima-se da consciência que se deixou encher por uma plenitude anônima (BLANCHOT, 2011, p. 287).

Segundo Tatiana Salem Levy (2011, p. 28), em Blanchot "não existe mais a separação clássica entre real e imaginário como duas temporalidades distintas, pois o real é sempre real e imaginário ao mesmo tempo". Em vez de tornar o objeto novamente presente, de remeter direta e posteriormente a ele - o que, segundo uma concepção clássica do imaginário, seria a função primeira da imagem - a imagem, segundo Blanchot, o deixa cada vez mais ausente. $\mathrm{O}$ objeto não nos é dado, mas, ao contrário, afastado de nós. A característica da imagem seria, então, como vimos, a de afirmar as coisas em sua desaparição, a de tornar presente a ausência que a funda.

Podemos, portanto, tornar-nos reféns das imagens, presos e fixados a elas, como em uma semelhança: é quando elas são amarradas às significações, aos sentidos dados de antemão, à representação, quando uma imagem é tornada crença ou remetida a uma tautologia esvaziada, quando acreditamos que o que vemos não nos olha, quando, diante do vazio a que nos lança a imagem, tratamos de preenchê-lo com sentidos que apenas repetem um horror ao vazio.

Assim, podemos por um lado acreditar que a imagem seria como uma superfície, planaridade dura, intransponível. Imagem verticalizada. Tornamo-nos fixos na imagem que olhamos. Aqui a imagem é mapa cujas fronteiras estão muito bem demarcadas. A imagem é representação dos espaços, acredita-se que ela pode contê-los, pode conter os sentidos de um território em sua totalidade. Um mapa que se desenha numa distância sem contato. Como uma praia, vista do 
alto de uma aeronave: de longe, sem contato, seus contornos parecem nunca mudar, nunca sofrer as alterações da maré. Por outro lado, se tomarmos a imagem como um volume, subitamente se poderia perfurá-la, abrir nela uma fissura, um buraco, tornando-a uma profundidade que se pode escavar. Segundo Didi-Huberman (1998, p. 87), talvez só haja imagem a pensar para além do princípio de superfície: "a espessura, a profundidade, a brecha, o limiar e o habitáculo - tudo isto obsidia a imagem". Aqui a imagem se faz no percurso de uma topologia, como quando se percorre um litoral, pés em contato com a areia da praia, no flagrante de seu constante movimento, no qual as ondas que carregam a areia e a trazem de volta, mantêm essa imagem em constante devir. Um território que se compõe e se desmancha incessantemente, escavado pelas águas. A cada dia seus desenhos, seus contornos, são outros.

\section{A Dupla Distância do Olhar}

Trataremos agora de expor o conceito de Dupla Distância do Olhar em Georges Didi-Huberman, que encontra relações imediatas com o conceito de Duplicidade da Imagem em Maurice Blanchot. Em ambos essa relação dupla com a imagem se dá em uma distância que envolve o olhar em um sentido epistêmico, crítico, de suspensão da dialética. Não se trata de uma duplicidade como em planos opostos que se pode escolher, mas como forças que atravessam nossas relações com a imagem.

Entretanto, para chegarmos ao conceito de dupla distância do olhar em Didi-Huberman, não poderemos deixar de passar por Walter Benjamin (1994), de quem o filósofo francês extrai conceitos valiosos tomados em uma medida sempre contemporânea, como veremos. Se em Blanchot a duplicidade se refere por um lado à representação e por outro a um escoamento do jogo representacional, em Didi-Huberman, com a ajuda de Benjamin, a imagem coloca a própria dialética em suspensão. Didi-Huberman, que como observamos não abandona as palavras de Maurice Blanchot, coloca-se por seu turno no seio de uma crise epistemológica por que passam a História, a Teoria e a Crítica da Arte no contemporâneo. Crise em que se pronunciou o fim da arte, o fim da história da arte. Crise em que a própria arte coloca em questão seu lugar dentro da linguagem, seu lugar de errância, de devir.

De forma parecida a Blanchot, quando ele nos fala da duplicidade da imagem, para Didi-Huberman (1998, p. 163), o objeto se dá ver numa "dupla distância". Distância que nada tem a 
ver com coordenadas espaciais, mas com um modo particular de conceber estes objetos em sua "aparição", ou seja, em seu "aparecer" ao olhar. O que se compõe é uma relação especial com o espaço e o tempo. Essa ideia de aparição é concebida a partir do conceito de aura, que Didi-Huberman revisita em Walter Benjamin, e que ele define da seguinte maneira:

Uma trama singular de espaço e de tempo, ou seja, propriamente falando, um espaçamento tramado - e mesmo trabalhado, poderíamos dizer, tramado em todos os sentidos do termo, como um sutil tecido ou então como um acontecimento único, estranho, que nos cercaria, nos pegaria, nos prenderia em sua rede. [...] A aura seria, portanto, como um espaçamento tramado do olhante e do olhado, do olhante pelo olhado (DIDI-HUBERMAN, 1998, p. 147).

Dessa forma, fala-se em sua dupla distância, pois se trata de um duplo olhar (poder do olhar atribuído ao próprio olhado pelo olhante). Trata-se de um paradoxo: sob nossos olhos, mas fora de nossa visão, por isso, nessa dupla distância, o conceito e o sentido de espaço assumem uma concepção radical, desde onde ele não se deixa medir, objetivando-se. O espaço é distante, é profundo e permanece inacessível - por excesso ou por falta - quando está sempre aí, ao redor e diante de nós: a aura, portanto, consiste nessa trama particular de tempo e espaço que se processa, se eleva, se suspende diante de uma imagem.

Encontramos essa relação da imagem com o espaço, como aborda Didi-Huberman, em Vasto como a noite, capítulo de A conversa Infinita - a ausência de Livro, quando Blanchot aborda a Poética do Espaço, de Gaston Bachelard. Nessas páginas, quando se refere ao espaço em sua relação com a imagem, não é apenas lhe atribuindo um valor de imaginário, ou seja, assumindo que a imaginação dele se apodera em suas experiências reais ou irreais, mas que "nos aproximamos, pela imagem, do próprio espaço da imagem, desse exterior que é a sua intimidade, esse horrível dentro e fora que é o verdadeiro espaço" (BLANCHOT, 2010, p. 64). Esse espaço da imagem é sem imagem, fala imaginária e não do imaginário, porque aqui o imaginário fala sem falar de imagens ou por imagens. O espaço da imagem é o nível em que imagem, imaginário e imaginação não possuem mais significação distinta. Ou seja, tomando imaginário e imaginação como os aspectos temporais da imagem, vemos a mesma invocação de uma trama de tempo e espaço em que não haveria como esperar que o fluxo 
de sentidos que a imagem abre poderia se estabilizar em uma imagem acabada, uma imagem síntese, mas antes em uma imagem que põe a dialética em suspensão. Uma imagem crítica, como a denomina Walter Benjamin (1994).

Voltando ao conceito de aura de Benjamin, não podemos passar tão rapidamente pelo mesmo sem que, antes de seguirmos ao ponto que nos interessa, nos detenhamos um momento para acompanhar o que Didi-Huberman explicita ao colocar em questão a aplicabilidade histórica desse conceito em relação ao seu caráter estético e ético, expondo uma análise da posição do próprio Benjamin quanto ao mesmo. Segundo Didi-Huberman (1998), para o filósofo alemão o conceito de aura está ligado a uma contradição diante da modernidade:

Por um lado, a aura como valor cultual propriamente dito, a aura como vetor de ilusão e como fenômeno de crença era atacada por uma crítica vigorosa que lhe opunha um modernismo militante. Mas, por outro lado, Benjamin criticou também, como sabemos, a própria modernidade em sua incapacidade de refigurar as coisas, em sua 'atrofia da experiência' ligada ao mundo mecanizado (o mundo da reprodução generalizada, justamente, aquele mesmo cujo interminável paroxismo vivemos hoje). O modernismo militante parece então substituído por uma espécie de melancolia crítica que vê o declínio da aura sob o ângulo de uma perda, de uma negatividade esquecedora na qual desaparece a beleza (DIDI -HUBERMAN, 1998, p. 154).

Didi-Huberman (1998) explicita, portanto, que esse valor cultural da aura não está ligado a um sentido religioso, é preciso refutar a ideia de aparição que está ligada à anexação ao mundo da crença. Para tanto, ele sugere secularizar o conceito de Benjamin. Para Didi-Huberman, a aura surge como aparição da distância que compõe o espaço entre o que vemos e o que nos olha.

Então, nossa experiência fundamental será de fato experimentar sua aura, ou seja, na aparição de sua distância e o poder desta sobre nosso olhar, sobre nossa capacidade de nos sentir olhados. O espaço sempre é mais além, mas isso não quer dizer que seja alhures ou abstrato, uma vez que ele está, que ele permanece aí. Quer dizer simplesmente que ele é uma "trama singular de tempo e de espaço" (DIDI-HUBERMAN, 1998, p. 165). 
Eis aqui o que interessa esclarecer: a dupla distância - a aura - é aquilo que na obra está em obra quando vemos: é quando aquilo que vemos também nos olha. Essa dupla distância se abre diante de nós senão como aquilo que vem à luz e que ao mesmo tempo obscurece o olhar - ela se desdobra em um paradoxo. Segundo Didi-Huberman (1998, p. 150):

Quando o trabalho do simbólico consegue tecer essa trama de repente "singular" a partir de um objeto visível, por um lado ele o faz literalmente "aparecer" como um acontecimento visual único, por outro o transforma literalmente: pois ele inquieta a estabilidade mesma de seu aspecto, na medida em que se torna capaz de chamar uma lonjura na forma próxima ou supostamente possível da posse. E assim a desapossa como objeto de um ter, e lhe confere por diferença uma qualidade de quase sujeito, de quase ser - "levantar os olhos", aparecer, aproximar-se, afastar-se [...]

Vemos explicitada a relação entre Blanchot e Didi-Huberman no que se refere a essa ideia de "aparição" do objeto. Nos dois, o que faz aparecer o objeto como imagem é essa "distância", que não é apenas espacial, mas igualmente temporal, distância dada pelo confronto entre a imagem em sua origem e o sentido sempre original da imagem.

Didi-Huberman define essa "aparição" como uma experiência singular de ser mantido à distância por uma obra de arte, ou ainda aproximando-se em um afastamento. Com Didi-Huberman, compreendemos que a aura nada tem a ver com um estado psíquico ou espiritual que emanaria do objeto olhado e que muito menos seria induzido por aquele que olha. Ela está antes nessa dupla distância, "distância crítica", que faz aparecer uma presença sem espaço. "Distância crítica” porque coloca sujeito e objeto em crise diante dessa presença, dessa aparição - aparição em que somos lançados à imagem. Não uma imagem do objeto, nem muito menos uma imagem do sujeito, mas uma imagem crítica que coloca ambos, sujeito e objeto, em questão. Observamos aqui, mais uma vez, que Didi -Huberman e Blanchot se encontram: objeto e sujeito são lançados a um inapreensível que os envolve diante desta relação.

Essa situação crítica a que a imagem nos lança permite seguir ao ponto que interessa ressaltar: a ideia de imagem crítica, em Didi-Huberman, ou de imagem dialética, como ele a lê em Walter Benjamin, que pensa a imagem como aquilo que coloca a própria dialética em suspensão. Eis o que ele escreve: 
[...] Em outros termos, a imagem é a dialética em suspensão. Pois, enquanto a relação do presente com o passado é puramente temporal, contínua, a relação do Pretérito com o Agora presente é dialética: não é algo que se desenrola, mas uma imagem fragmentada. Somente as imagens dialéticas são imagens autênticas (isto é, não arcaicas); e a língua é o lugar onde é possível aproximar-se delas. (BENJAMIN, 1994 apud Didi-Huberman, 1998, p. 114).

Trata-se de pensar a imagem a partir dessa crise em que sua presença na distância coloca o sujeito, não como uma imagem através da qual ele possa possuir um objeto, e nem como uma imagem que conteria uma verdade sobre o objeto. Nas palavras de Didi-Huberman (1998, p. 172), trata-se de "uma imagem em crise, uma imagem que critica a imagem, e por isso de uma imagem que critica nossas maneiras de vê-la, na medida em que, ao nos olhar, ela nos obriga a olhá-la verdadeiramente".

Quando estamos diante de um objeto - diante de uma obra de arte - podemos crer possuí-lo, tê-lo como tal. Entretanto, seu contexto, seu lugar de origem e de possibilidade jamais tivemos e jamais teremos. Podemos apenas, como escreve Didi-Huberman (1998, p. 176), "dirigir um olhar talvez melancólico sobre a espessura do solo - do 'meio' - no qual esses objetos outrora existiram”. Essas imagens críticas exigem uma nova posição do olhar, e, portanto, daquele que olha: nem devoção positivista ao objeto, nem nostalgia metafísica, não mais buscar reproduzir esse objeto do olhar, nem mesmo representá-lo. É então justamente nesse momento que a imagem solicita a palavra, tal como afirma Benjamim, como vimos há pouco. Diante dessa imagem crítica, a língua tornase o lugar desde onde podemos nos aproximar dela.

E aqui podemos novamente lembrar a fórmula de Blanchot: escrevemos sob o fascínio da imagem. Fórmula que perseguimos neste ensaio. $O$ filósofo francês que sub-repticiamente nos fala da imagem, faz dela a questão central da palavra. Nenhuma afirmação há em Blanchot que rebaixe a imagem diante do poema, diante da palavra. É o que ele afirma em passagens simples, que como pequenos tesouros encontramos entre as camadas de sua escrita, tal como aqui:

Do mesmo modo que não vejo imagens no poema, pois no poema tudo é imagem e tudo se faz imagem, seria igualmente necessário dizer que toda imagem é também todo o poema, 
sendo seu centro único, sua aparição súbita e momentânea, sua preferência discreta, sua contenção. (...) Nada então de mais glorioso no poema do que a imagem, uma vez que ela é o seu segredo e sua profunda, sua infinita reserva (BLANCHOT, 2010, p. 63).

Tais afirmações fazem da imagem a questão central nas investigações filosóficas acerca da literatura em Blanchot, mas ao mesmo tempo tornam seus escritos preciosos para acessar um pensamento acerca da imagem que concerne aos movimentos de escrita. É assim que, numa pequena nota de rodapé, ele afirma: "a imagem, em sua pureza de elemento, parece prestar-se à escrita, ao mesmo tempo em que desejaria ser-lhe estrangeira" (BLANCHOT, 2010, p. 64). Esse estrangeirismo da imagem é dado por sua infinita capacidade de ser para nós um enigma, mas tal qual nos sugere Blanchot, sendo enigma, a imagem nos lança enigmas:

Ela solicita, por seu ar de pergunta, toda nossa aptidão a responder, fazendo valer as garantias de nossa cultura assim como os interesses de nossa sensibilidade. [...] Esse desdobramento parece então ser seu desígnio e sua natureza: ela é essencialmente dupla, não apenas signo e significado, mas figura do não figurável, forma do informal, simplicidade ambígua que se dirige àquilo que há de duplo em nós e reanima a duplicidade em que nós nos dividimos, em que nós nos juntamos indefinidamente (BLANCHOT, 2010, p.65-66).

Solicitar nossa aptidão para responder parece requerer exortar a palavra, seja a palavra da fala ou da escrita, mas não como resposta, e sim como exigência. Uma exigência de criar, pois se essa palavra não responde, ela inventa, cria. E novamente vemos a que esse sentido duplo da imagem se refere: figura do não figurável, forma do informal. Seria assim que a imagem faz o mundo nela reentrar para que, dali, de sua profundidade, dessa divisão em que ela nos coloca entre forma e informe, possamos indefinidamente nos reunir na tentativa de algum comum.

Esse fascínio pela imagem de que fala Blanchot, essa imagem crítica, tal como aparece em Didi-Huberman, coloca a palavra em um movimento incansável, interminável, um movimento que nos obriga a criar. Blanchot acredita que é o lugar onde a literatura é lançada e Didi-Huberman, onde a própria História e Crítica da Arte são divulgadas. Como olhar a ima- 
gem sem ser capturado por seu fascínio eventual e levado a uma crise? Crise que exige do próprio pensamento um posicionamento radical.

\section{A Imagem Crítica e a Palavra}

Para Didi-Huberman a tarefa do historiador de arte envolve um trabalho crítico da imagem, que diante do objeto de sua pesquisa, "num único lance, o produzirá emitindo uma imagem como se emite um lance de dados. Uma queda, um choque, uma conjunção arriscada". A imagem crítica, como ele escreve, "nos obriga a escrever esse olhar, não para 'transcrevê-lo', mas para constituí-lo” (DIDI-HUBERMAN, 1998, p. 172).

Dessa forma, podemos afirmar que escrever sobre arte, sobre uma obra, é escrever sobre sua imagem e nessa perspectiva esse gesto exige uma nova relação do discurso com a obra, ou ainda uma nova forma de discurso, capaz de transformar e de inquietar duravelmente os campos discursivos circundantes. O que se coloca aqui é uma relação inédita das obras de arte com a sua "compreensão" que, como escreve Didi-Huberman, é tarefa como a que Walter Benjamin nunca cessou de querer inventar ou reinventar:

Seja como for, Benjamin nos deu a compreender a noção de imagem dialética como forma e transformação, de um lado, como conhecimento e crítica do conhecimento, de outro. Ela é, portanto, comum - segundo um motivo um tanto nietzschiano - ao artista e ao filósofo. [...] Ela mostra justamente o motor dialético da criação como conhecimento e do conhecimento como criação. A primeira sem o segundo correndo o risco de permanecer no nível do mito (da crença), e o segundo correndo o risco de permanecer no nível do discurso sobre a coisa (positivista, por exemplo) (DIDI-HUBERMAN, 1998, p. 179).

A imagem crítica oferece a possibilidade, portanto, de superar o pensamento do dilema, a necessidade de separar, hierarquizar ou mesmo de realizar uma escolha entre imagem e palavra. Para Didi-Huberman os pensamentos binários, os pensamentos do dilema, são incapazes de perceber que não há que se escolher entre o que vemos e o que nos olha, mas há que se inquietar com o entre: como um coração que bate, no qual a dilatação e contração - o movimento de diástole e sísto- 
le (como aquele das ondas do mar sobre a areia, a que nos referimos acima, movimento que frustra infinitamente qualquer configuração de um mapa fixo) - mantém o corpo respirando, mantém o ar saindo e entrando por seus buracos, aerando a superfície e a profundidade de um corpo esburacado.

Talvez seja este o momento em que a arte volta-se para si mesma: momento em que a palavra pode entrar no tempo da imagem e a imagem no tempo da palavra. Momento em que "a obra criticada possa exercer ela mesma a função de crítica, e que o crítico faça ele mesmo obra", como escreve Didi-Huberman (1998, p. 187). Para Benjamin, "articular historicamente o passado não significa conhecê-lo 'como ele de fato foi'. Significa apropriar-se de uma reminiscência, tal como ela relampeja no momento de um perigo" (BENJAMIN, 1994, p. 224). Vemos assim, porque Didi-Huberman escreve o seguinte:

O crítico de arte, com efeito, se acha diante de seu próprio vocabulário como diante de um problema de faíscas a produzir de palavra a palavra, friccionando, por assim dizer, palavras com palavras. Como encontrar, como produzir com palavras a conflagração que, na imagem, nos olha? Esse é exatamente o problema - que Benjamin figurava praticamente como um problema de escultura, de baixo-relevo ou de gravura [ou de escavação, como ousamos inferir], como um problema de suporte martelado: "encontrar palavras para o que se tem diante dos olhos, como isso pode ser difícil. Mas, quando vem, elas batem o real com pequenas marteladas até que nele tenham gravado a imagem como numa chapa de cobre". (DIDI-HUBERMAN, 1998, p. 184).

O que Didi-Huberman nos sugere com Benjamin é transformar a História da Arte, ou ainda o discurso histórico sobre os objetos de arte, transformando a relação entre crítica e obra, entre história e obra:

Como num verdadeiro diálogo crítico entre uma e outra, e não num rebatimento totalitário de uma sobre a outra (rebatimento que define a situação acadêmica como tal). Um diálogo crítico em que cada parte seria capaz de pôr em questão e de modificar a outra, modificando a si mesma (DIDI-HUBERMAN, 1998, p. 187).

Para Didi-Huberman, o que se permitirá configurar aí será uma confiança ao pensamento que as imagens podem 
produzir, ou seja, compreender as imagens como produtoras, geradoras de pensamento, assim como aquele que as palavras produzem, tão aceito no senso comum, e ao qual uma ciência positivista e cartesiana dá o primado. E ainda, por seu turno e não menos importante, uma confiança quanto à capacidade criadora da palavra, capacidade plástica do pensamento, mais precisamente é isso o que escreve o historiador francês, e que desejamos ressaltar: "uma confiança epistêmica concedida às imagens, tanto quanto uma confiança formal e criadora concedida à palavra" (DIDI-HUBERMAN, 1998, p. 187).

Na imagem, em seu volume e espessura, escavar uma brecha, um buraco, construir um habitáculo, uma toca, como escrevem Gilles Deleuze e Félix Guattari, em Kafka, por uma literatura menor (2014), lugar de onde fazer saltar seus enunciados e suas visibilidades, como escreve Foucault em Arqueologia do Saber (2007): seria assim que poderíamos reagir à captura mútua que sempre parece obsidiar as relações entre palavra e imagem, criando, nesse entrelaçamento, fissuras que façam escoar os sentidos contidos, que façam escoar o território retido pelos mapas que acreditam possível uma fixidez. Cartografar, mapear, constelar são movimentos e não atribuições do jogo que podemos assumir com a palavra diante da imagem. Movimentos de dar passagem às imagens e palavras que tanto nas obras de Blanchot como de Didi-Huberman, não implicam em uma hierarquização, uma submissão, e isso precisamente porque a imagem é a dialética em suspensão, não apenas porque não há que se escolher, mas igualmente porque não se pode acreditar, na palavra ou na imagem, qualquer possibilidade de síntese de uma em relação à outra. Ambas configuram um regime de visibilidade e enunciados possíveis, que as fazem saltar de suas entranhas. Assim, a imagem não ganha autonomia em relação à palavra, mas encontra na palavra um lugar de criação, de invenção. Movimento que a coloca numa relação infinita com a palavra. Há em Blanchot uma frase enigmática, espécie de linha de chegada e de partida que tentamos percorrer neste ensaio. Linha, portanto, que não se fecha em uma conclusão, que se aproxima da chegada para torná-la novamente seu ponto de partida. Ele diz: "toda vez que o que está em questão é a imagem, o que buscamos entender é a questão, mas não ainda a imagem, na qual desponta o neutro" (BLANCHOT, 2010, p. 66).

No presente artigo, para problematizar o conceito de imagem fabricamos uma dobra entre Maurice Blanchot e Georges Didi-Huberman. O agenciamento conceitual entre os dois 
autores teve como apoio principal a duplicidade da imagem em Blanchot e a dupla distância do olhar em Didi-Huberman. A partir da leitura apresentada buscamos compor um pequeno mapa onde o pensamento de ambos aparece posicionado diante da imagem. Nossa intenção foi desenhar um modo de pesquisar a imagem ao que tudo indica convergente nesses autores. Ao enunciar tais paisagens, contudo, somos levados a compreender que tais relações com a imagem laçam sujeito e objeto a uma permanente instabilidade. Trata-se de um modo aberto de operar uma pesquisa, de operar com as palavras diante da imagem, em que o sujeito tende a se desfazer de si pela imagem, ambos oscilando, claudicantes, sem definição, distantes de um desfecho. Movimento desde onde escrevemos sob o fascínio da imagem, desde onde a linguagem é lançada ao infinito.

\section{Referências}

BAVCAR, Evgen; TESSLER, Elida; CARON, Muriel. Uma câmera escura atrás de outra câmera escura: entrevista com Evgen Bavcar. In: A Invenção da Vida. Porto Alegre: Artes e Ofícios, 2001.

BENJAMIN, Walter. Obras Escolhidas - Magia e Técnica, Arte e Política. 7. ed. Tradução Sergio Paulo Rouanet. São Paulo: Editora Brasiliense, 1994.

BLANCHOT, Maurice. O espaço literário. Tradução Álvaro Cabral. Rio de Janeiro: Rocco, 2011.

- A conversa infinita - A palavra plural (palavra de escrita). Tradução Aurélio Guerra Neto. São Paulo: Escuta, 2010.

DELEUZE, Gilles; GUATTARI, Félix. Kafka - Por uma literatura menor. Tradução Luiz B. Orlandi. Belo Horizonte: Autêntica Editora, 2014.

DIDI-HUBERMAN, Georges. O que vemos, o que nos olha. Tradução Paulo Neves. São Paulo: Editora 34, 1998.

. De semelhança a semelhança. Tradução Maria José Werner Salles. Revista Alea, v. 13, n. 1, jan./jun. 2011. Disponível em:< http://www.scielo.br/scielo.php?script=sci arttext\&pid=S1517-106X2011000100003 >. Acesso em: 20 jul. 2013.

FOUCAULT, Michel. Arqueologia do Saber. 7. ed. Tradução Luiz Felipe Baeta Neves. Rio de Janeiro: Forense Universitária, 2007.

LEVY, Tatiana Salem. A experiência do fora, Blanchot, Foucault e Deleuze. Rio de Janeiro: Civilização Brasileira, 2011. 
Recebido em: 27/07/2017

Aprovado em: 20/11/2017

\section{LILIAN HACK}

lilianhack@gmail.com

Universidade Federal do Rio Grande do Sul, Rio Grande do Sul, Porto Alegre, Brasil. Doutoranda em Artes Visuais pela UFRGS, na área de concentração em História, Teoria e Crítica de Arte. Mestre pela mesma instituição. Integra os grupos de pesquisa Fundar: grupo de pesquisa sobre instauradores da arte contemporânea; Vida Que Vem: Arte, Política e Processos de Subjetivação; Laboratório de Pesquisa em Psicanálise, Arte e Política. Foi professora substituta na UFPEL. Em suas pesquisas dedica-se às relações entre palavra e imagem nos processos de escrita, arte e vida e processos de criação.

\section{ÉDIO RANIERE DA SILVA}

edioraniere@gmail.com

Universidade Federal de Pelotas, Rio Grande do Sul, Pelotas, Brasil. Doutor em Psicologia Social e Institucional pela UFRGS. Coordenador Adjunto do Curso de Psicologia da UFPEL. Membro da ABRAPSO e da ANPEPP. Suas principais pesquisas concentram-se em dois eixos temáticos: 1) Ressonâncias entre Arte e Psicologia; 2) Socioeducação. Coordena o projeto de pesquisa Vida que Vem: arte, política e processos de subjetivação; e o projeto de extensão Socioeducação (en) cena: Agenciamentos entre Psicologia Social e Teatro. 